\title{
Evaluation of Combined Effect of Mercerized and Dyed Yarns on Physical Properties of Plain Single Jersey Knitted Fabrics
}

\author{
S. M. Elrys, A. El-Hossini, and A. M. EL-Hadidy \\ Mansoura University, Faculty of Engineering, Textile Department, Mansoura, Egypt \\ Correspondence should be addressed to S. M. Elrys; samah_elrys@yahoo.com
}

Received 5 August 2015; Accepted 18 November 2015

Academic Editor: Hu Hong

Copyright ( 92015 S. M. Elrys et al. This is an open access article distributed under the Creative Commons Attribution License, which permits unrestricted use, distribution, and reproduction in any medium, provided the original work is properly cited.

\begin{abstract}
A combined effect of mercerized and dyed yarns on physical properties of plain single jersey knitted fabrics has been studied. Plied cotton yarn was produced and mercerized at different $\mathrm{NaOH}$ concentrations and temperatures. Then, this yarn was bleached and dyed with two types of dyes, vat dyeing and reactive dyeing. Each of mechanical and color properties were measured to these treated yarns. Plain single jersey knitted fabrics were produced from these treated yarns. The total evaluation of the properties for plain single jersey fabrics was measured by using radar chart method. It was found that the highest area of radar chart, which represents the total physical properties, is achieved at $32^{\circ} \mathrm{Be}^{\prime}$, in case of vat dyeing. Besides, analysis of variance (AVOVA) and MANOVA were applied to illustrate which of the properties would be affected by $\mathrm{NaOH}$ con. and types of dyeing for yarns and fabrics.
\end{abstract}

\section{Introduction}

The quality of end products like fabrics depends on the quality of their components like yarns. Textile finishing processes are usually used to improve the quality of materials. Among these, mercerization is one of the most important wet finishing processes of cotton materials, as it improves handling and appearance of cotton fibers to simulate the superior properties of synthetic fibers. In addition, Mercerization treatment improves dye ability and luster required for appearance, smoothness and strength required for ability of processing such as sewing threads.

These properties are the most important ones needed to materials for competition with other products.

There are many methods of mercerization where it can be applied to yarns or fabrics. Depending on tension, it can be done in the slack state or under tension state. Depending on temperature, it can be done under high temperatures which is called hot mercerization or under normal temperatures which is called normal mercerization. Also, it can be applied in hank, cheese, and single-end mercerization.

However, all of these methods of mercerization are applied by treating the materials with caustic soda solution at a certain concentration and temperature depending on the type of applied method. Each of these methods has its merits and demerits. The extent of changes that occur depends on the processing time, caustic concentration, temperature, and degree of polymerization, source of cellulose, the physical state of the cellulose, slack or tension treatment, and the degree of tension [1].

Dyeing is another wet process that influences yarn and fabric properties. Cotton and other cellulosic fibers are dyed with direct, sulphur, vat, reactive, and more types than for any other fiber. Each of these classes of dye has its own application methods, dyeing characteristics, cost, fastness properties, colour range, advantages, and disadvantages. Reactive dyes, particularly those used for dyeing cotton, have become one of the major classes of dyes because of their good washing fastness, their bright shades, and their versatile batch and continuous dyeing methods. Furthermore, vat dyes are one of the oldest types of dye. Vat dyes in particular give dyeing on cellulosic fibers with the best overall fastness properties [2].

Single jersey knitted fabrics are used to make underwear and outerwear garments such as T-shirts. The knitted fabrics undergo a series of different processing treatment 
like bleaching, scouring, dyeing, softener padding, and relax drying. These processes are carried out to impart a particular property related to that process like scouring for absorbency, bleaching for whiteness, dyeing for imparting colour to fabric, and finishing for improving softness and handling the fabric [3].

It can be clear that each wet process has its special influence on the properties of the treated yarns or fabrics. However, studying the combined effect of these wet processes on the physical properties of yarns and plain singles jersey fabrics produced from these treated yarns is rare.

\section{Review of Literature}

Mercerization is originally discovered by John Mercer in 1844. From this time, mercerization has a major interest to researchers because of its advantages.

Akhbari et al. investigated the parameters influencing mercerization using RSM method, in order to increase the tensile strength of mercerized yarn [4]. Samei et al. compared the effects of hot mercerization on open-end and ring spun yarns in slack and under tension conditions. Mercerized yarns were bleached and dyed with reactive dye [5]. Gemci applied mercerization process on cotton fabrics with three different weaving patterns using three different time periods and three different processes under factory conditions to examine the dimension stability [6]. Moghassem and Valipour investigated the effects of four mercerization treatment parameters, namely, alkali concentration, time of treatment, bath temperature, and mercerization tension on dimensional properties of plain knitted fabric produced from cotton yarn [7]. Hasani studied the effect of different finishing processes like bleaching, dyeing and softening on mechanical and surface properties of cotton knitted fabrics [8].

Sameii et al. studied the effect of mercerization parameters on cotton fabrics made up of open-end yarns. Reactive dyes were used for dyeing. The results showed that tensile strength of fabrics could be improved in mercerization process [9]. The effect of different wet processing stages and sequences on the physical, dimensional, and dyeing properties of the single jersey knitted fabrics are produced by Murugesh and Selvadass [3].

From the previous studies, there are many researches about the effect of mercerization conditions only on the mercerized yarns. Some of the researchers studied the effect of mercerization and dyeing on mercerized yarns. Others studied the effect of mercerization parameters only on properties of fabrics. Also, little researchers studied the relation between properties of mercerized yarns and properties of plain single jersey knitted fabrics produced from them.

However, the combined effect of mercerization variables and variables of the following finishing operations is scanty. Consequently, this research attempts to expand the study of the effect of mercerization besides some types of dyeing on the produced yarns and properties of plain single jersey knitted fabrics produced from these yarns.

\section{Experimental}

3.1. Materials. Plied ring spun cotton yarn with a count of 20/2 Ne was produced. It was spun from Egyptian cotton G86 with single twist factor $\alpha e=3.6$ and plied twist factor $\alpha e=3.5$.

\subsection{Methods}

3.2.1. Mercerization. Mercerization was done on Jaeggli mercerizing yarn machine. Yarn hanks were treated with caustic soda concentration ranging from $26^{\circ} \mathrm{Be}^{\prime}$ to $34^{\circ} \mathrm{Be}^{\prime}$ with $2^{\circ} \mathrm{Be}^{\prime}$ intervals, using wetting agent $[(6-8) \mathrm{g} / \mathrm{L}$ of FLORANIT 4028 of Pulcra Chemical]. Temperature of treatment was firstly changed by using $19^{\circ} \mathrm{C}$ and $24^{\circ} \mathrm{C}$. Both applied tension and time of treatment were constant. To remove the excess caustic soda after the treatment, the yarn hanks were washed with hot and cold water. The hanks were then neutralized with acetic acid solution $(0.5 \mathrm{~cm} / \mathrm{L})$ to remove any residual alkali. Yarns were finally rinsed with cold water, squeezed with centrifugal forces, dried at $110^{\circ} \mathrm{C}$ for $2 \mathrm{hrs}$.

3.2.2. Bleaching. Mercerized yarns were bleached in an exhaustion procedure, the bleaching bath containing $0.5 \%$ hydrogen peroxide, $2 \%$ sodium hydroxide, $2 \%$ asbicon (detergent used as assistant factor), and 1\% Egypttool (wetting agent). The bleaching was carried out at $100^{\circ} \mathrm{C}$ for $1 \mathrm{hr}$. Acetic acid was used for neutralization.

3.2.3. Dyeing. Dyeing with vat and reactive dyes were carried out by exhaustion procedure.

(a) Reactive Dyeing. EcoFix.Blue. $\mathrm{R}(1.5 \%), \mathrm{Na}_{2} \mathrm{CO}_{3}(5 \mathrm{~g} / \mathrm{L})$, and $\mathrm{NaCl}(20 \mathrm{~g} / \mathrm{L})$ were adjusted at $50^{\circ} \mathrm{C}$ and then raised to $60^{\circ} \mathrm{C}$ and maintained at this temperature for $90 \mathrm{~min}$ to dye as reactive dyeing. Dyed samples were then washed in a soap solution and then boiled and softened by using fatty acid and, finally, squeezed and dried at $100^{\circ} \mathrm{C}$.

(b) Vat Dyeing. Yarns were dyed in a solution containing India Blue CLF (vat dye) (1.5\%), $\mathrm{NaOH}(0.1 \%)$, and sodium hydrosulphite $(5 \mathrm{~g} / \mathrm{L})$. As known, vat dyeing is based on the principle of converting water-insoluble vat dye by alkaline reduction to a water-soluble leuco compound having affinity to cotton. Sodium hydrosulphite is used in the reduction process at $60^{\circ} \mathrm{C}$ and then raised to $80^{\circ} \mathrm{C}$ for $20 \mathrm{~min}$ and then washed. Finally, it is oxidized by using $\mathrm{H}_{2} \mathrm{O}_{2}$ at $50^{\circ} \mathrm{C}$ for $30 \mathrm{~min}$, washed, and softened by using fatty acid.

3.2.4. Knitting Process. Plain single jersey knitted fabrics were produced on Stoll flat knitting machine, G 12, and loop length $0.6 \mathrm{~cm}$. The specification of the pretreated produced samples can be illustrated in Table 1 .

In addition, two samples of Plain single jersey knitted fabrics were produced from without mercerized, bleached, vat, and reactive dyed yarns. These two samples were used for comparison. 
TABLE 1: Fabrics production plan.

\begin{tabular}{lccccc}
\hline \multirow{2}{*}{ Types of dyeing } & \multicolumn{5}{c}{$\mathrm{NaOH}$ conc. $\left(\mathrm{Be}^{\prime}\right)$} \\
& 26 & 28 & 30 & 32 & 34 \\
\hline Vat dyeing & $\sqrt{ }$ & $\sqrt{ }$ & $\sqrt{ }$ & $\sqrt{ }$ & $\sqrt{ }$ \\
Reactive dyeing & $\sqrt{ }$ & $\sqrt{ }$ & $\sqrt{ }$ & $\sqrt{ }$ & $\sqrt{ }$ \\
\hline
\end{tabular}

3.3. Testing Methods. Testing methods were carried on both of yarns and finished plain single jersey knitted fabrics as follows.

3.3.1. Testing Methods of Yarns. Breaking load and extension of yarns were measured by using USTER Tensorapid 4 . Color strength of yarns was observed by using Data color International SF 600 at D65. Yarn abrasion resistance was measured according to ASTM D6611.

3.3.2. Testing Methods of Fabrics. A sensitive digital balance device with accuracy of two digits was used to measure the weight of the samples and then fabric weight in $\mathrm{g} / \mathrm{m}^{2}$ was estimated. Thickness of fabric samples was measured by using K094 SDL Atlas digital thickness gauge tester according to ASTM D1777, Standard Test Method for Thickness of Textile Material.

The fabric bursting strength and elongation due to burst were tested using H5KT Tinius Olsen universal testing machine using ASTM D 3787 bursting strength in knitted goods standard test method. Fabric abrasion resistance of fabrics was measured by using Taber Abrasion (Rotary Platform) tester according to ASTM D3884. The air permeability was tested using M021A SDL Atlas air permeability tester using ASTM D 737 standard test method. Fabric stiffness was measured by using the circular bend procedure according to ASTM D 4032. K/S was measured using D412G1 color i5 spectrophotometer using daylight condition (D65). K/S is used to evaluate the depth of dyed color after mercerization.

The Shrinkage value was defined by (1), for American AATCC number 135-1987

$$
\mathrm{SH}(\%)=\left[\frac{\left(L-L_{0}\right)}{L_{0}}\right] \times 100,
$$

where $L_{0}$ is the length of the sample before laundering and drying and $L$ is the length of the sample after laundering and drying.

\section{Experimental Results and Discussion}

4.1. Results of Yarns. At the end of each treatment process, the yarn samples were collected and tested for some of the mechanical and color properties. The experimental results of yarns are compared to grey yarn as illustrated in the following equation:

$$
\text { Change }(\%)=\left[\frac{(T-G)}{G}\right] \times 100,
$$

where $T$ is the treated samples of yarns and $G$ is the grey sample.

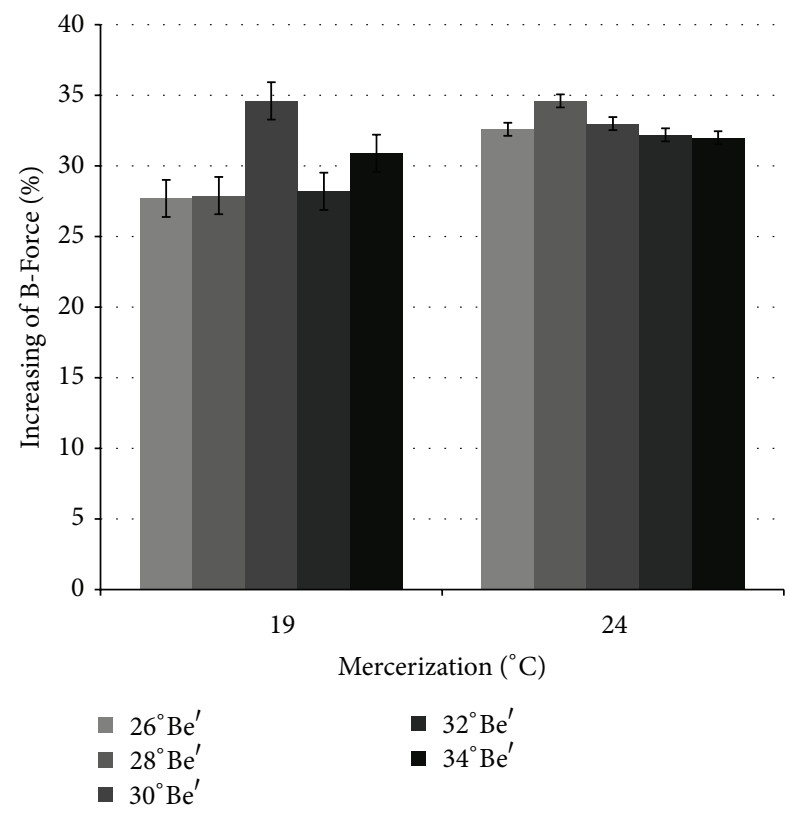

Figure 1: Effect of mercerization temperature and $\mathrm{NaOH}$ conc. on yarn breaking load.

4.1.1. Effect of Mercerization Temperature and $\mathrm{NaOH}$ Concentration on Yarn Breaking Load. Figure 1 shows the effect of temperature of mercerizing and $\mathrm{NaOH}$ concentration on the breaking load of yarns. It can be clearly seen that breaking load rose from $27.7 \%$ to $34.6 \%$ with an average value of $31.37 \%$. In general, there is an increase in the strength in case of temperature $24^{\circ} \mathrm{C}$ more than temperature $19^{\circ} \mathrm{C}$. In case of temperature $19^{\circ} \mathrm{C}$, the highest value of breaking load occurs at $30^{\circ} \mathrm{Be}^{\prime}$, which is nearly equal to the highest value at $24^{\circ} \mathrm{C}$ which occurs at $28^{\circ} \mathrm{Be}^{\prime}$. This means that there is a relationship between mercerization temperature and $\mathrm{NaOH}$ concentration. In AS, with increasing temperature and with lower $\mathrm{NaOH}$ concentration, the same value can be obtained with increasing $\mathrm{NaOH}$ concentration at lower temperature.

Of course, lower concentration with higher temperature is economically better. Consequently, the temperature $24^{\circ} \mathrm{C}$ is selected to be studied where the average increase value reaches $32.88 \%$. The main reason of increasing the breaking load after mercerization process because cotton fibers are modified during mercerizing process and transformed from cellulose I to cellulose II. Fibers become more amorphous and less crystalline.

4.1.2. Effect of Mercerization and Dyeing on Breaking Load of Mercerized Yarns. Figure 2 shows the effect of both vat and reactive dyeing on the breaking load for the mercerized yarn at $24^{\circ} \mathrm{C}$ and at different $\mathrm{NaOH}$ concentrations. As shown, there is an increase generally in breaking load after vat dyeing more than reactive dyeing compared to bleaching.

Results showed that the breaking load rose from $8.6 \%$ to $27.9 \%$ with the average value $16.24 \%$ in case of vat dyeing.

Also, results showed that the breaking load increased to $24.1 \%$ in case of reactive dyeing because of the effect of 


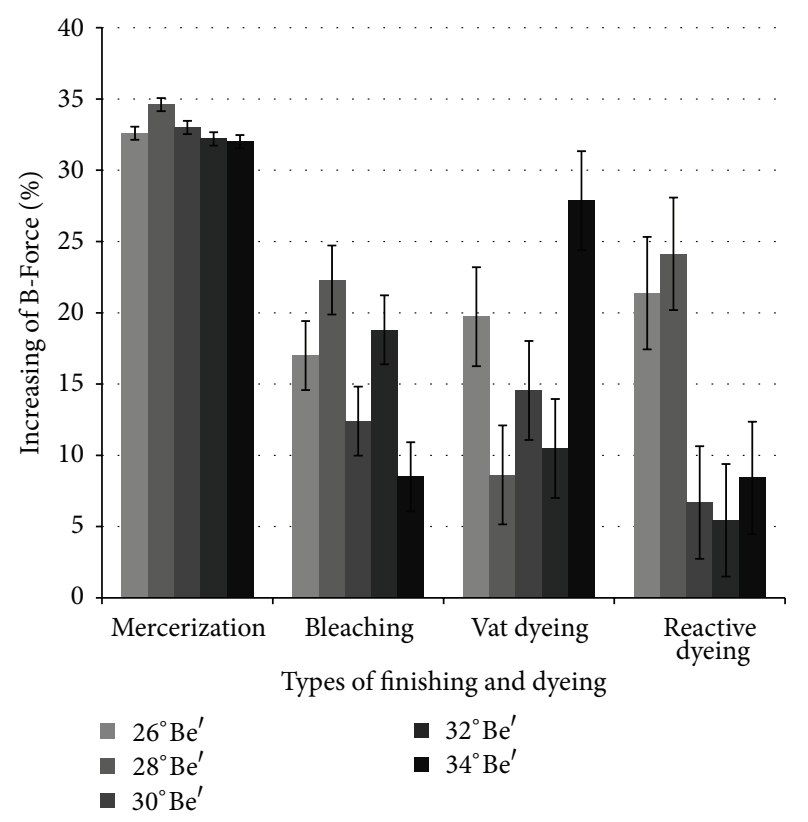

FIGURE 2: Effect of vat and reactive dyeing on breaking load of mercerized yarns.

chemical bonds between the dye and the fibers. Moreover, reactive dye can also be bonded with more than one fiber consequently increasing the tensile strength. The increase in breaking load in case of reactive ranges from $5.5 \%$ to $24.1 \%$ with an average value of $13.22 \%$.

The highest value in the breaking load for vat dyeing occurs at $34^{\circ} \mathrm{Be}^{\prime}(27.9 \%)$ but for reactive dyeing it occurs at $28^{\circ} \mathrm{Be}^{\prime}(24.1 \%)$.

On the other hand, the lowest value in breaking load for vat dyeing occurs at $28^{\circ} \mathrm{Be}^{\prime}(8.6 \%)$ but for reactive dyeing it occurs at $32^{\circ} \mathrm{Be}^{\prime}(5.5 \%)$.

As mercerizing process leads to the increase of dyeing absorption because of breaking the hydrogen bonds between the fibers in the crystalline regions and converting them to amorphous regions. This increase in vat dyeing is arranged during washing with alkali soap after dyeing process. In addition, the increase of these spaces between fibers with the presence of vat dyeing may be the reason for the rise of the breaking load.

4.1.3. Effect of Mercerization and Dyeing on Yarn Breaking Extension. Figure 3 shows the effect of mercerization and dyeing on the mercerized yarn at different $\mathrm{NaOH}$ concentrations and at $24^{\circ} \mathrm{C}$. As shown mercerizing process affects the breaking extension negatively.

From the results after mercerization, breaking extension decreases from $-16.7 \%$ to $-22.5 \%$ with average value $-20.5 \%$. However, after bleaching breaking extension decreases from $-19.4 \%$ to $-31.4 \%$ with average value $-24.4 \%$.

Also there is a decrease after vat dyeing from $-19.5 \%$ to $-31.2 \%$ with average value $-25.3 \%$. Moreover, breaking extension decreases sharply after reactive dyeing from $-16.1 \%$ to $-35.2 \%$ with average value $-29.1 \%$. The decrease percentage

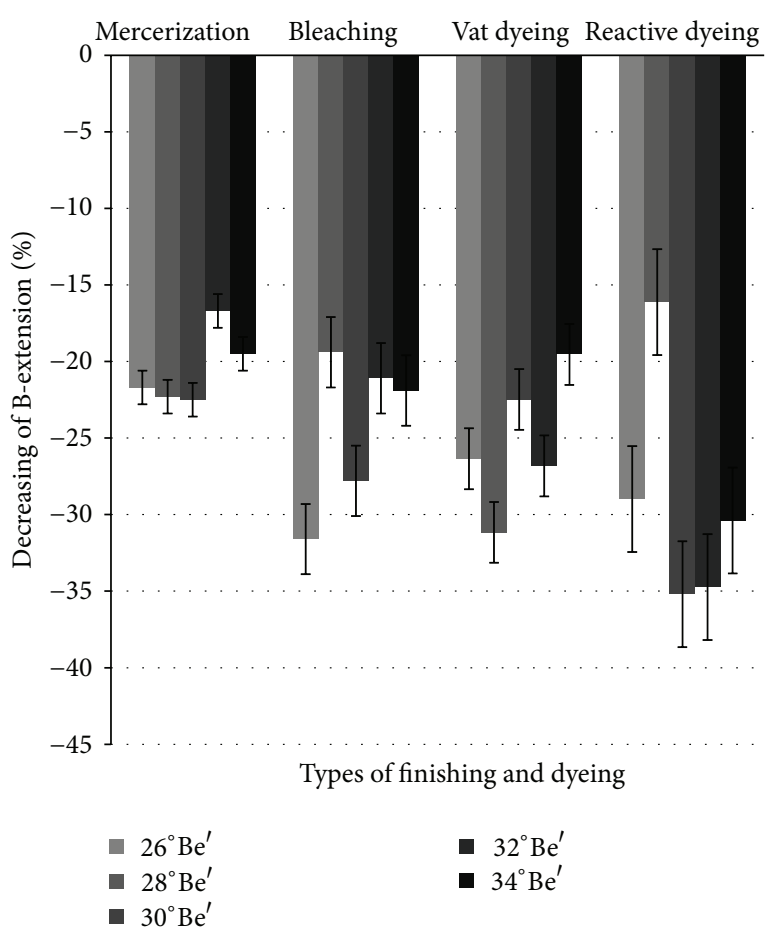

FIGURE 3: Effect of types of finishing on yarn breaking extension.

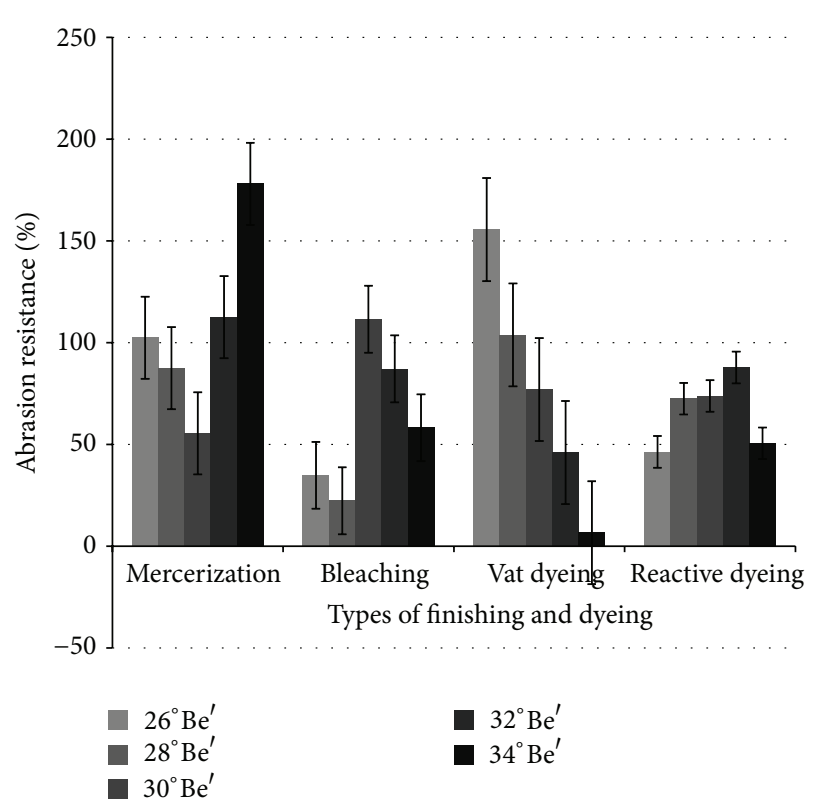

FIGURE 4: Effect of mercerization and dyeing on yarn abrasion resistance.

of breaking extension can be illustrated due to the axis parallel alignment of fibers in the yarn centre [10].

4.1.4. Effect of Mercerization and Dyeing on Yarn Abrasion Resistance. Figure 4 shows the effect of both mercerization and dyeing on abrasion resistance of yarns at different $\mathrm{NaOH}$ concentrations. It can be clearly seen that there is an increase in abrasion resistance of yarns after mercerization from $55 \%$ 


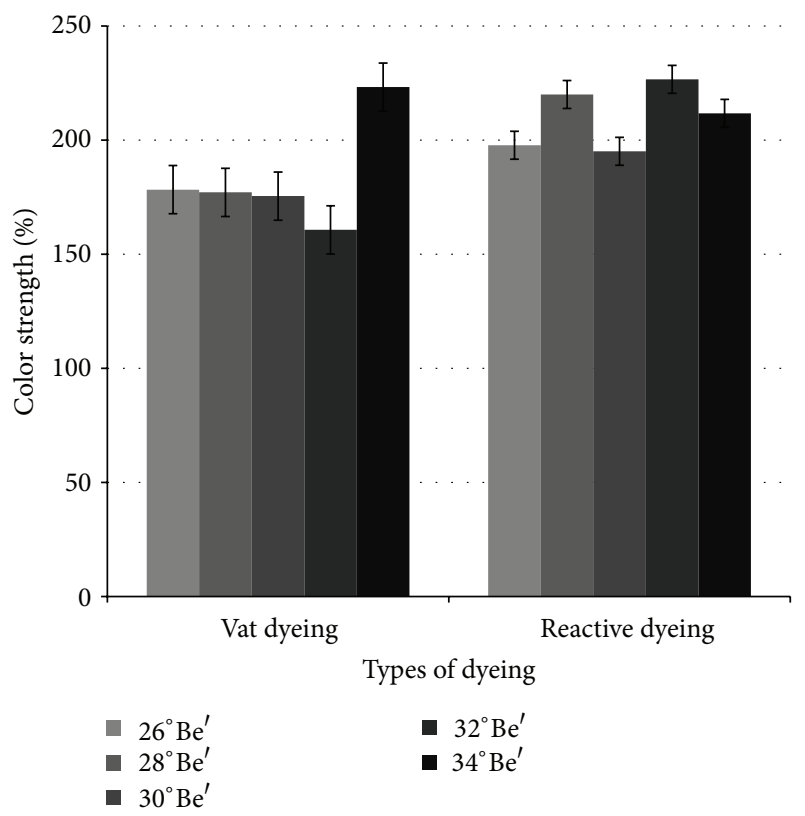

FIGURE 5: Effect of vat and reactive dyeing on color strength of mercerized yarns.

to $178 \%$. There is an increase after vat dyeing from $7 \%$ to $155 \%$, and after reactive dyeing from $46 \%$ to $87 \%$.

Abrasion of the yarn is followed by the gradual removal of fibers from the yarns when they are subjected to repeated distortion. Factors affecting the cohesion of the fibers in the yarn and yarn to yarn friction will have influence on the abrasion resistance. They mainly depend on the fiber surface, supramolecular structure of fibers, yarns surfaces, and yarn compressibility in addition to the magnitude of the normal pressure acting between them [11].

4.1.5. Effect of Vat and Reactive Dyeing on Color Strength of Mercerized Yarns. Figure 5 shows the effect of vat and reactive dyeing after mercerization at different $\mathrm{NaOH}$ concentrations and at $24^{\circ} \mathrm{C}$ on the color strength of yarns. In general, there is an increase in color strength in reactive dyeing more than vat dyeing. It can be clearly seen that color strength increased from $160.7 \%$ to $223.2 \%$ with average value $183 \%$ in case of vat dyeing because mercerizing process converts fibers to cylindrical shape leading to the increase of the spaces between the fibers, so the dye molecules can easily penetrate into the fibers and increase the color strength of this vat dye. Also, results showed an increase in color strength of reactive dyeing from $195.1 \%$ to $226.6 \%$ with average value $210.3 \%$ because molecules of this reactive dye are bonded with covalent bonds with the fibers, so the color strength of the dye increases.

The highest value in vat dyeing occurs at $34^{\circ} \mathrm{Be}^{\prime}(223.2 \%)$ and in reactive dyeing occurs at $32^{\circ} \mathrm{Be}^{\prime}(226.6 \%)$.

4.2. Results of Knitted Fabrics. Experimental results of fabric physical and colour properties are compared to the two

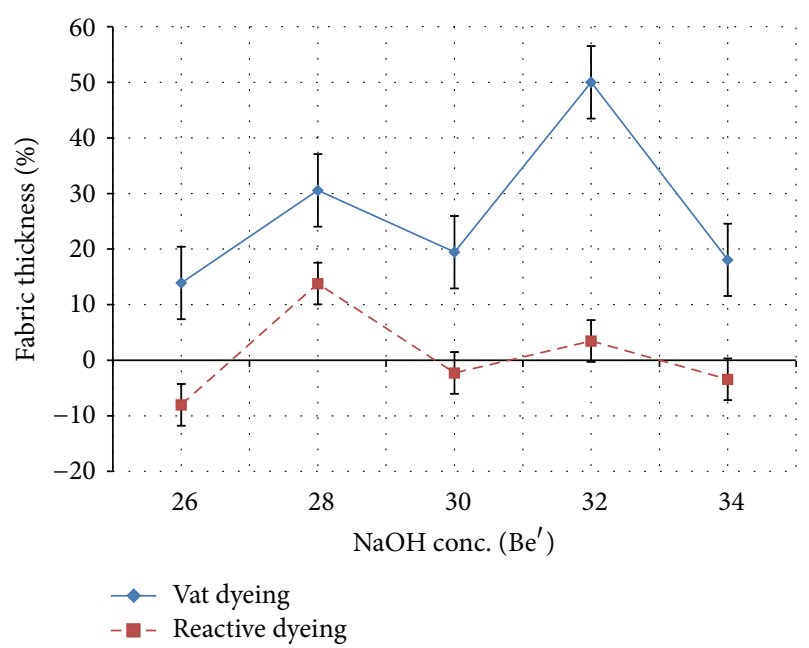

FIGURE 6: Effect of mercerization and dyeing on thickness of plain single jersey knitted fabrics.

unmercerized samples as illustrated in the following equation:

$$
\text { Change }(\%)=\left[\frac{(\mathrm{MD}-\mathrm{BD})}{\mathrm{BD}}\right] \times 100 \text {, }
$$

where MD is the mercerized, bleached, and dyed samples and $\mathrm{BD}$ is the unmercerized, bleached, and dyed samples, with the knowledge that each dyed sample is compared to its same type of dyed sample.

4.2.1. Fabric Thickness. Figure 6 shows the effect of both of mercerization and dyeing processes on the thickness of plain single jersey knitted fabrics. As shown, there is generally an increase in thickness in vat dyeing more than reactive dyeing with $26 \%$. The same effect of the thickness is obtained in both vat dyeing and reactive dyeing depending on $\mathrm{NaOH}$ concentration.

There is an increase in case of vat dyeing from $13.9 \%$ to $50 \%$ compared to vat standard sample, with average increase value $26.4 \%$, while, in case of reactive dyeing, the average increase value of thickness was $0.7 \%$ compared to reactive standard sample. The highest value of thickness at vat dyeing occurs at $32^{\circ} \mathrm{Be}^{\prime}$ and at reactive dyeing occurs at $28^{\circ} \mathrm{Be}^{\prime}$.

4.2.2. Fabric Weight. Figure 7 shows the effect of mercerization and dyeing on the weight of plain single jersey knitted fabrics. As shown, the same effect on the weight of fabrics in both dyeing with increasing $\mathrm{NaOH}$ concentration. As in the case of the thickness, the weight of fabrics at vat dyeing is more than that at reactive dyeing. As in the case of vat dyeing, increasing temperature of mercerization leads to increase of the swelling, converting crystalline regions to amorphous regions. Consequently, there are greater opportunities to soak up water moisture because of the increase of the free amounts of hydroxyl groups which forms the hydrogen bonds. On the other hand, there is a decrease in the weight in the case of reactive dyeing because increasing the temperature leads 


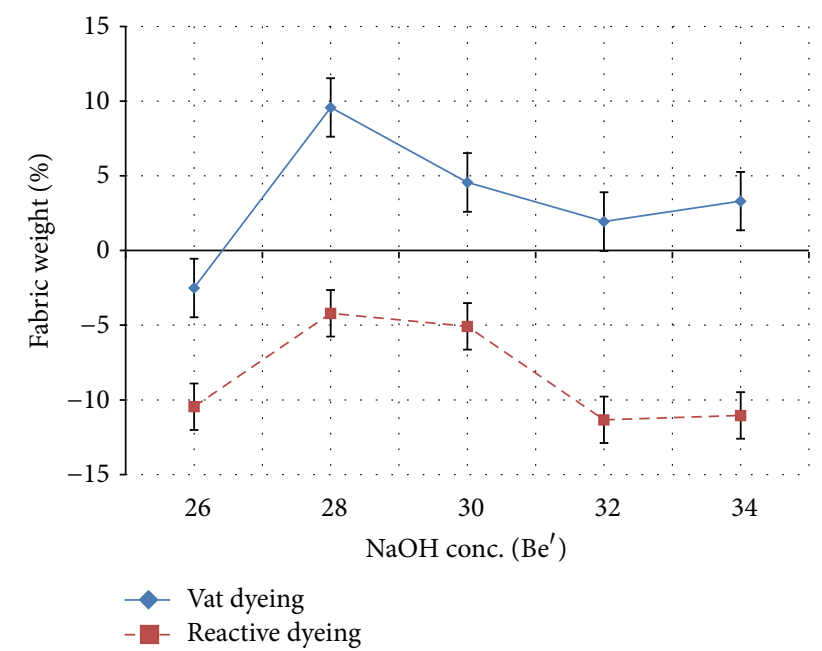

Figure 7: Effect of mercerization and dyeing on weight of plain single jersey knitted fabrics.

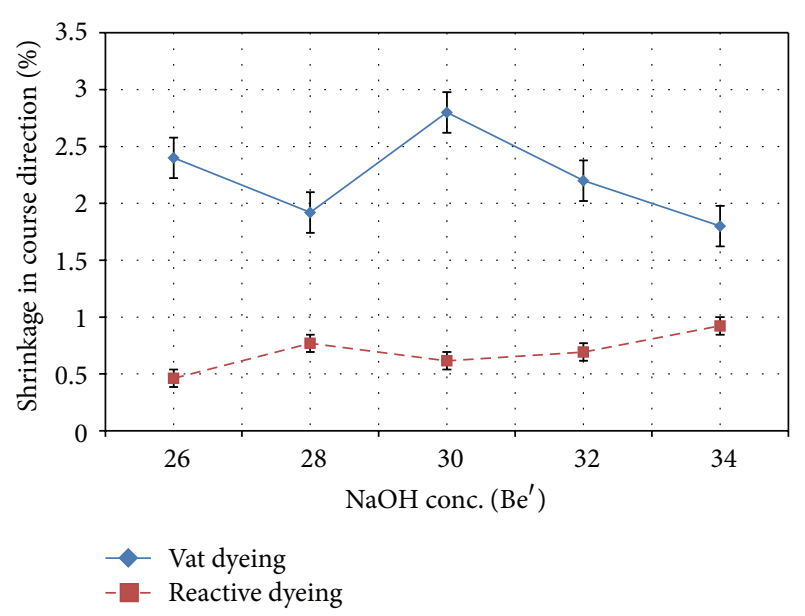

FIGURE 8: Effect of mercerization and dyeing on shrinkage in courses direction of plain single jersey knitted fabrics.

to the removal of starching materials and some of natural impurities materials.

The average increase value in case of vat dyeing is 3.4\%, but the average decrease value in case of reactive dyeing is $8.4 \%$.

4.2.3. Fabric Shrinkage. Figures 8 and 9 show the effect of mercerization and dyeing on the shrinkage in both wales and courses directions of plain single jersey knitted fabrics. It can be clearly seen that there is a rise in the shrinkage in length direction in case of vat more than reactive dyeing. This means that reactive dyeing is better in shrinkage in length direction. The increase in shrinkage in length in case of vat dyeing ranges from $1.8 \%$ to $2.8 \%$ with average value $2 \%$, but the increase in shrinkage in case of reactive ranges from $0.5 \%$ to $0.9 \%$ with average value $0.7 \%$.

Of course the opposite happened in courses direction for both vat dyeing and reactive dyeing. As shown in Figure 9,

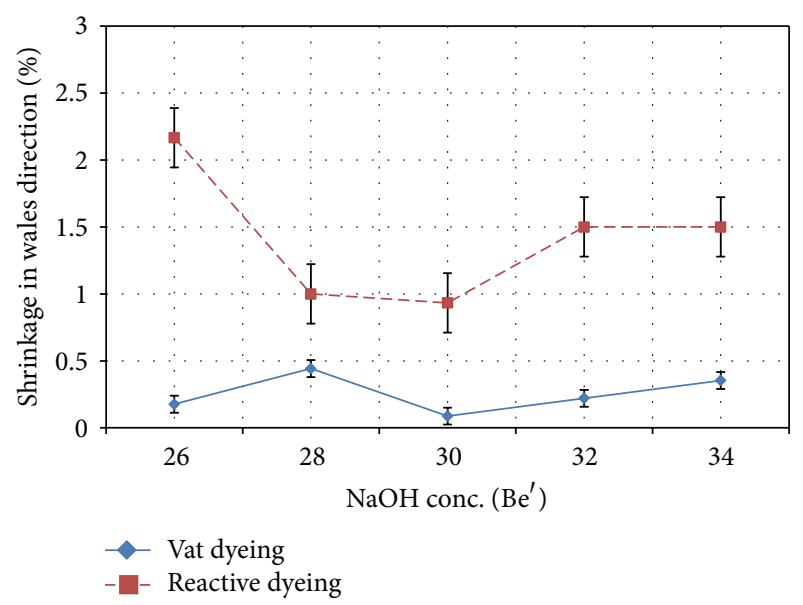

FIGURE 9: Effect of mercerization and dyeing on shrinkage in wales direction of plain single jersey knitted fabrics.

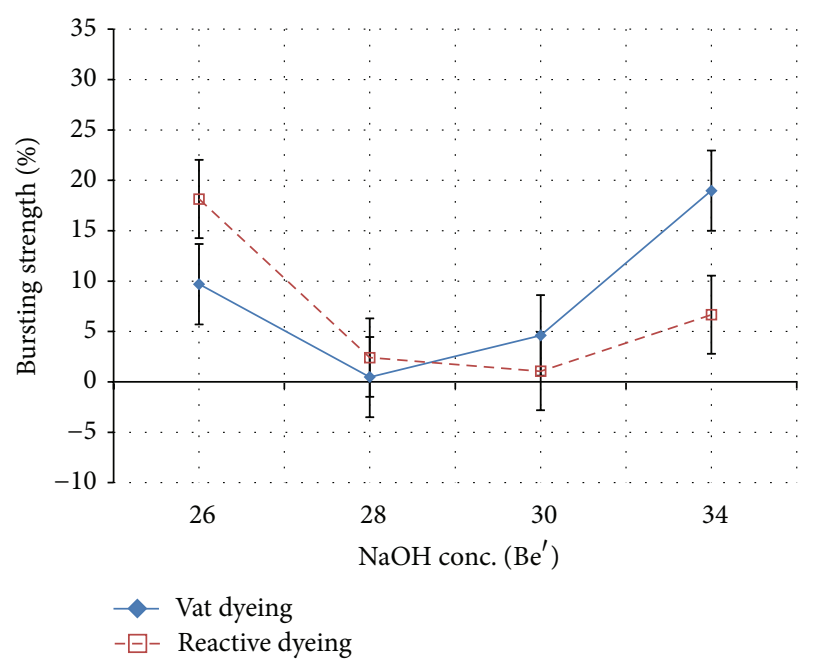

FIGURE 10: Effect of mercerization and dyeing on bursting strength of plain single Jersey knitted fabrics.

the increase in shrinkage in courses direction in case of reactive dyeing is more than vat dyeing. This means that vat dyeing is better in the shrinkage in width more than reactive dyeing. The best values for shrinkage in wales direction occur at $26^{\circ} \mathrm{Be}^{\prime}$ for reactive dyeing and at $34^{\circ} \mathrm{Be}^{\prime}$ for vat dyeing. Besides, the best values for shrinkage in courses direction occur at $26^{\circ} \mathrm{Be}^{\prime}$ for vat dyeing and at $30^{\circ} \mathrm{Be}^{\prime}$ for reactive dyeing.

4.2.4. Bursting Strength of Plain Single Jersey Fabrics. Figure 10 shows the effect of mercerization and dyeing on the bursting strength of plain single jersey knitted fabrics. The results showed that the same effect on the tensile strength happens for the two dyeing until a certain point, and then the opposite happens. In general, there is an increase in tensile strength of knitted fabrics in case of vat dyeing more than reactive dyeing. The increase of tensile strength in case of vat dyeing rises from $0.5 \%$ to $19 \%$ with average value $8.4 \%$. 


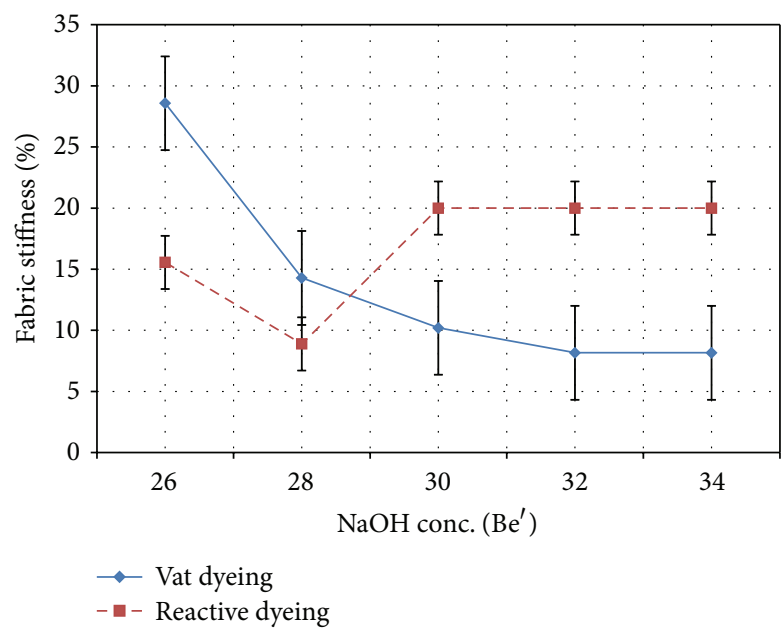

FIGURE 11: Effect of mercerization and dyeing on stiffness of plain single jersey knitted fabrics.

Also, increase of tensile strength in case of reactive dyeing ranges from $1.1 \%$ to $18.1 \%$ with average value $7.1 \%$. In fact, the increase in tensile strength is because of strengthening of the weak points along the fiber and also the modifications in orientation and consolidation of weak points.

The highest value of breaking load in case of vat dyeing occurs at $34^{\circ} \mathrm{Be}^{\prime}$, and the highest value in case of reactive dyeing occurs at $26^{\circ} \mathrm{Be}^{\prime}$.

4.2.5. Fabric Stiffness of Plain Single Jersey Fabrics. Figure 11 shows the effect of mercerization and dyeing on the stiffness of plain single jersey fabrics.

For vat dyeing, stiffness of plain jersey fabrics decreases with the increasing $\mathrm{NaOH}$ concentration. However, for reactive dyeing, the stiffness is decreased then increased and finally remained constant. The lowest value of stiffness at vat dyeing occurs at $34^{\circ} \mathrm{Be}^{\prime}$ and at reactive dyeing occurs at $28^{\circ} \mathrm{Be}^{\prime}$.

4.2.6. Abrasion Resistance of Plain Single Jersey Fabrics. Figure 12 shows the effect of mercerization and dyeing on the abrasion resistance of plain single jersey fabrics. As before in the bursting strength, the same effect on fabric abrasion resistance for the vat and reactive dyeing happens till $30^{\circ} \mathrm{Be}^{\prime}$; after that the opposite happens. Abrasion resistance fabric of vat dyeing increases from $1.7 \%$ to $62.9 \%$ with average value $26.8 \%$. In addition, abrasion resistance fabric of reactive dyeing increases from $4.8 \%$ to $55.1 \%$ with average value $20 \%$. The highest value of fabric abrasion resistance in case of vat dyeing occurs at $32^{\circ} \mathrm{Be}^{\prime}$, and the highest value of fabric abrasion resistance in case of reactive dyeing occurs at $26^{\circ} \mathrm{Be}^{\prime}$.

4.2.7. Air Permeability of Plain Single Jersey Fabrics. Figure 13 shows the effect of mercerization and dyeing on air permeability of plain single jersey fabrics. As shown, the increase in air permeability in case of vat dyeing is more than reactive dyeing. The results show that there is significant increase in air permeability in case of vat dyeing from $35 \%$ to $47 \%$ with

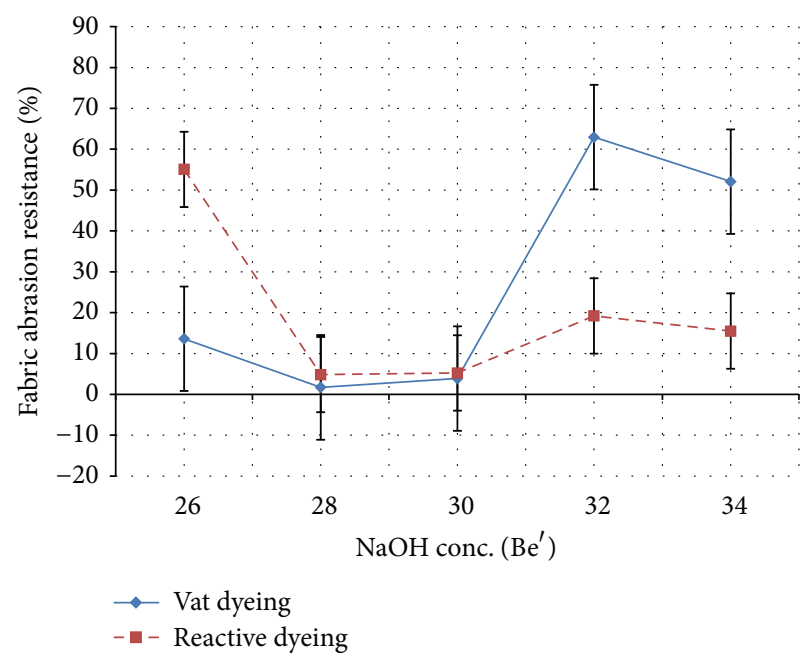

FIGURE 12: Effect of mercerization and dyeing on abrasion resistance of plain single jersey knitted fabrics.

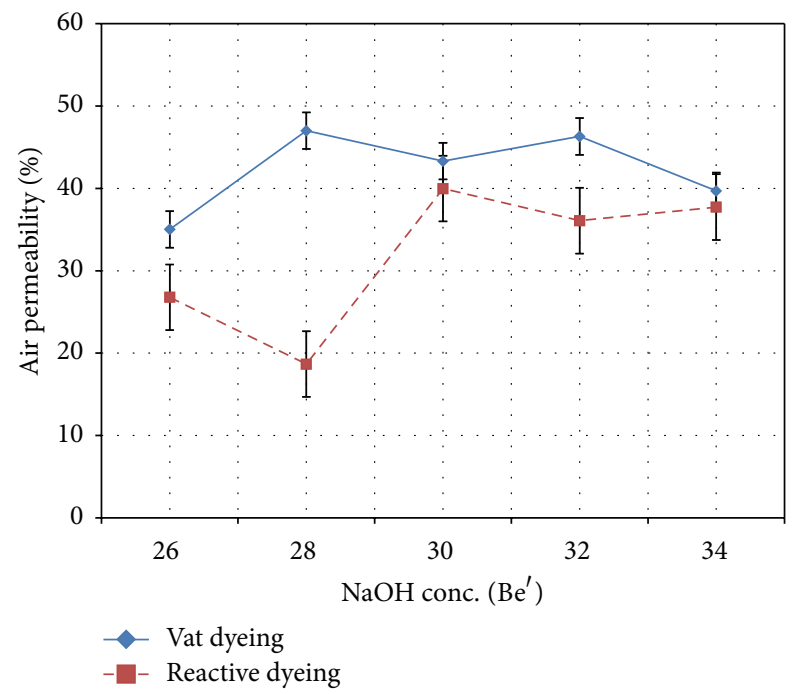

FIGURE 13: Effect of mercerization and dyeing on air permeability of plain single jersey knitted fabrics.

average value $42.3 \%$. Also, air permeability in case of reactive dyeing rises from $18.7 \%$ to $40 \%$ with average value $31.8 \%$. The highest value for air permeability in case of vat dyeing occurs at $28^{\circ} \mathrm{Be}^{\prime}$, and in case of reactive dyeing it occurs at $34^{\circ} \mathrm{Be}^{\prime}$. The increase of air permeability in both vat dyeing and reactive dyeing can be explained due to the fiber arrangement in the cross-section of the yarn.

4.2.8. K/S of Plain Single Jersey Fabrics. Figure 14 shows the effect of mercerization and dyeing on K/S of plain single jersey fabrics. As shown, vat dyeing is higher than reactive dyeing regarding $\mathrm{K} / \mathrm{S}$ values. The increase in $\mathrm{K} / \mathrm{S}$ values in case of vat dyeing ranges from $53 \%$ to $90 \%$ with average value $72.5 \%$.

Besides, the $\mathrm{K} / \mathrm{S}$ values in case of reactive dyeing rise from $4.8 \%$ to $43.7 \%$ with average value $27.5 \%$. The highest value 


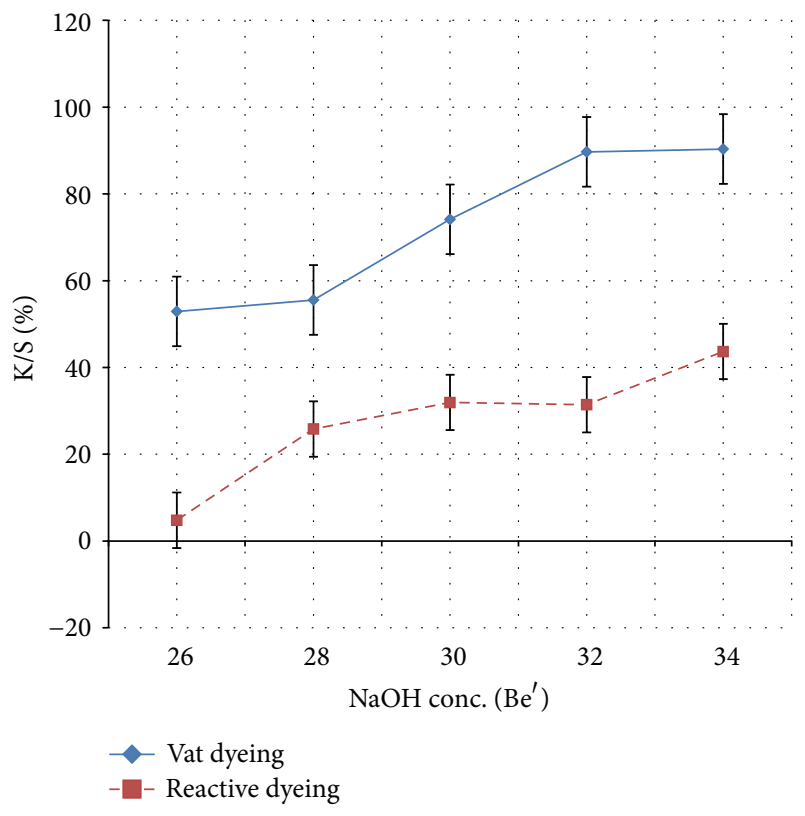

FIGURE 14: Effect of mercerization and dyeing on K/S values of plain single jersey knitted fabrics.

of $\mathrm{K} / \mathrm{S}$ in case of vat dyeing occurs at $34^{\circ} \mathrm{Be}^{\prime}$, and in case of reactive dyeing also occurs at $34^{\circ} \mathrm{Be}^{\prime}$.

The increase in color properties can be explained generally because of the destruction of crystalline regions during swelling and changes in microstructure and morphology.

\section{Analysis of Variance}

The influence of $\mathrm{NaOH}$ concentration on the properties of yarns after mercerization, bleaching, and vat and reactive dyeing was analyzed by the main effects analysis of variance (ANOVA). The results of $P$ values (variables have significant effect on the measured properties $P<0.05)$ are given in Table 2.

It was found that $\mathrm{NaOH}$ conc. had a significant effect on B-Force (after bleaching and dyeing), elongation (after each treatment), and abrasion resistance (after mercerization, bleaching, and only vat dyeing) of yarns.

Besides, the effect of both $\mathrm{NaOH}$ concentration and type of dyeing on the properties of plain knitted fabrics was analyzed by the main effects analysis of variance (MANOVA). The results of $P$ values of fabrics are shown in Table 3.

The results showed that $\mathrm{NaOH}$ concentration had a significant effect on the fabric thickness, bursting strength, fabric weight, abrasion resistance, and air permeability of plain knitted fabrics. On the other hand, the types of dyeing had a significant effect on fabric weight, shrinkage in course direction, bursting strength, and abrasion resistance of plain knitted fabrics.
TABLE 2: Effect of $\mathrm{NaOH}$ conc. on yarn properties.

\begin{tabular}{lc}
\hline Type of test & $\begin{array}{c}P \text { value of } \\
\mathrm{NaOH} \text { conc. }\end{array}$ \\
\hline B-Force after mercerization & 0.358 \\
B-Force after bleaching & 0.007 \\
B-Force after vat dyeing & 0.000 \\
B-Force after reactive dyeing & 0.013 \\
Elongation after mercerization & 0.000 \\
Elongation after bleaching & 0.000 \\
Elongation after vat dyeing & 0.000 \\
Elongation after reactive dyeing & 0.000 \\
Abrasion resistance after mercerization & 0.000 \\
Abrasion resistance after bleaching & 0.000 \\
Abrasion resistance after vat dyeing & 0.004 \\
Abrasion resistance after reactive dyeing & 0.147 \\
\hline
\end{tabular}

TABLE 3: Effect of $\mathrm{NaOH}$ conc. and types of dyeing on the properties of plain knitted fabrics.

\begin{tabular}{lcc}
\hline Types of test & $\begin{array}{c}P \text { value of } \\
\mathrm{NaOH} \text { conc. }\end{array}$ & $\begin{array}{c}P \text { value of types } \\
\text { of dyeing }\end{array}$ \\
\hline Fabric thickness & 0.000 & 0.084 \\
Fabric weight & 0.002 & 0.027 \\
Shrinkage in wales direction & 0.228 & 0.070 \\
Shrinkage in courses direction & 0.719 & 0.032 \\
Bursting strength & 0.000 & 0.001 \\
Fabric stiffness & 0.684 & 0.166 \\
Abrasion resistance & 0.000 & 0.000 \\
Air permeability & 0.031 & 0.257 \\
\hline
\end{tabular}

\section{Overall Evaluation of Yarn and Fabric Properties}

Hypothesis testing was used to know if the best properties of yarns occur at the same variables for the produced knitted fabrics or not. This was considered the null hypothesis, while the alternative hypothesis occurred when the yarns highest area of radar chart does not occur at the same variables which represent the fabric highest area of radar chart.

Figures 15 and 16 show the total evaluation of the properties for yarns by using Performance Diagram method based on the absolute values. It was found that the highest area of radar chart occurred at $26^{\circ} \mathrm{Be}^{\prime}$ in case of vat dyeing as shown in Table 4. The lowest area of Performance Diagram in case of vat dyeing occurred at $32^{\circ} \mathrm{Be}^{\prime}$. The highest area of Performance Diagram in case of reactive dyeing occurred at $32^{\circ} \mathrm{Be}^{\prime}$, but the lowest area is achieved at $34^{\circ} \mathrm{Be}^{\prime}$.

Figures 17 and 18 show the total evaluation of the properties for plain single jersey fabrics by using radar chart method based on absolute values. It was found that the highest area of Performance Diagram, which represents the total physical properties, is achieved at $32^{\circ} \mathrm{Be}^{\prime}$, in case of vat dyeing as shown in Table 5. On the contrary, the lowest area 


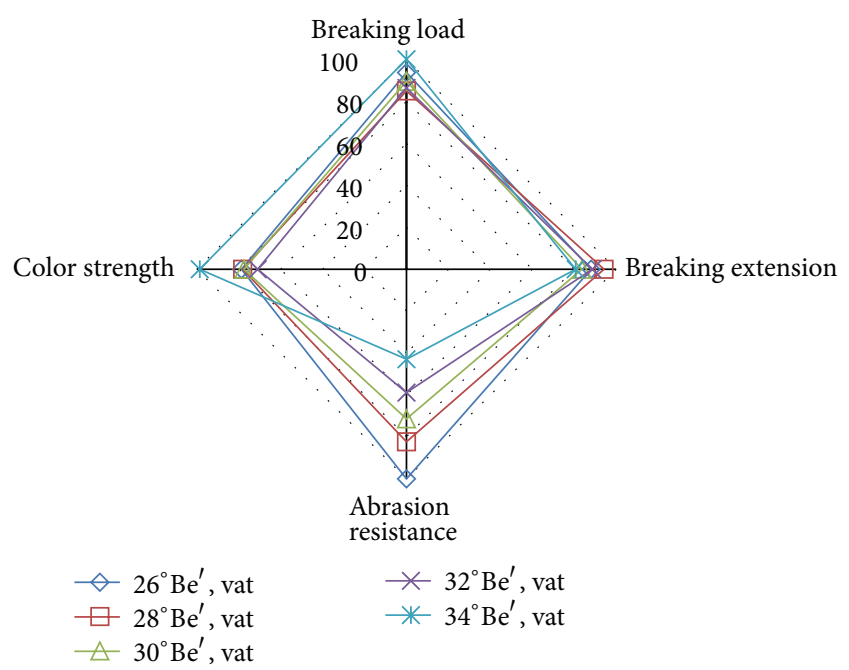

FIGURE 15: Overall evaluation of yarn properties at vat dyeing.

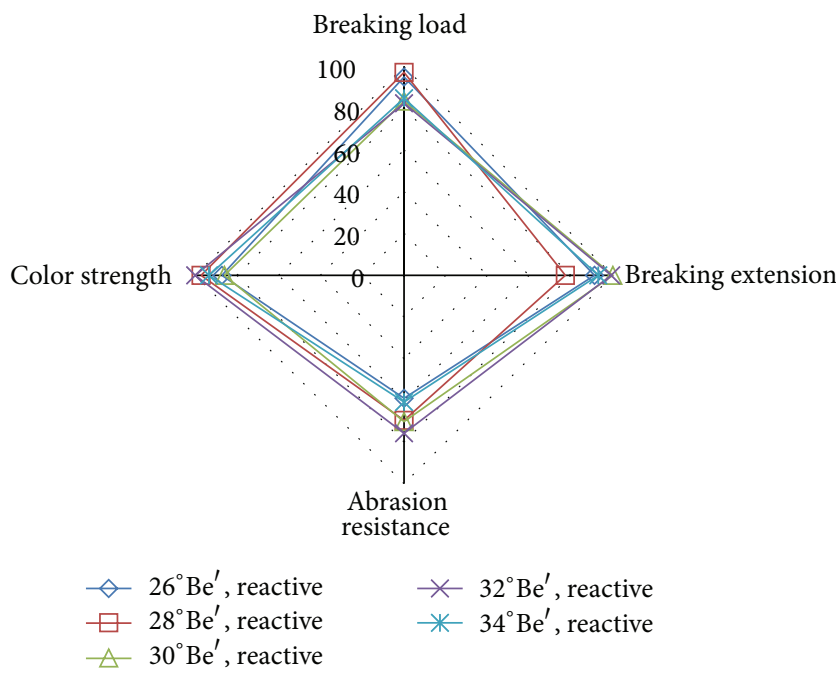

FIGURE 16: Overall evaluation of yarn properties at reactive dyeing.

TABLE 4: Total area of overall yarn properties.

\begin{tabular}{lccccc}
\hline \multirow{2}{*}{ Types of dyeing } & \multicolumn{5}{c}{$\mathrm{NaOH}$ conc. $\left(\mathrm{Be}^{\prime}\right)$} \\
& 26 & 28 & 30 & 32 & 34 \\
\hline Vat dyeing & $81 \%^{*}$ & $72 \%$ & $65 \%$ & $58 \%$ & $64 \%$ \\
Reactive dyeing & $69 \%$ & $73 \%$ & $71 \%$ & $79 \%$ & $68 \%$
\end{tabular}

${ }^{*}$ Actual area/ideal area.

of Performance Diagram in case of vat dyeing occurred at $26^{\circ} \mathrm{Be}^{\prime}$.

The average of improvement in the overall physical properties in case of vat dyeing is $65 \%$.

The highest area of Performance Diagram in case of reactive dyeing is achieved at $26^{\circ} \mathrm{Be}^{\prime}$; the lowest area occurred at $34^{\circ} \mathrm{Be}^{\prime}$. The average improvement in the overall physical properties in case of reactive dyeing is $57 \%$.

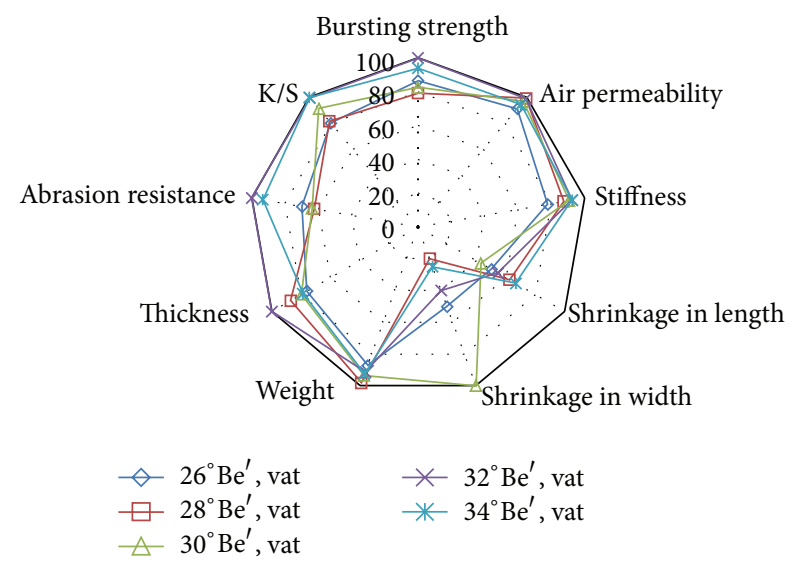

FIgURE 17: Overall evaluation of fabric properties at vat dyeing.

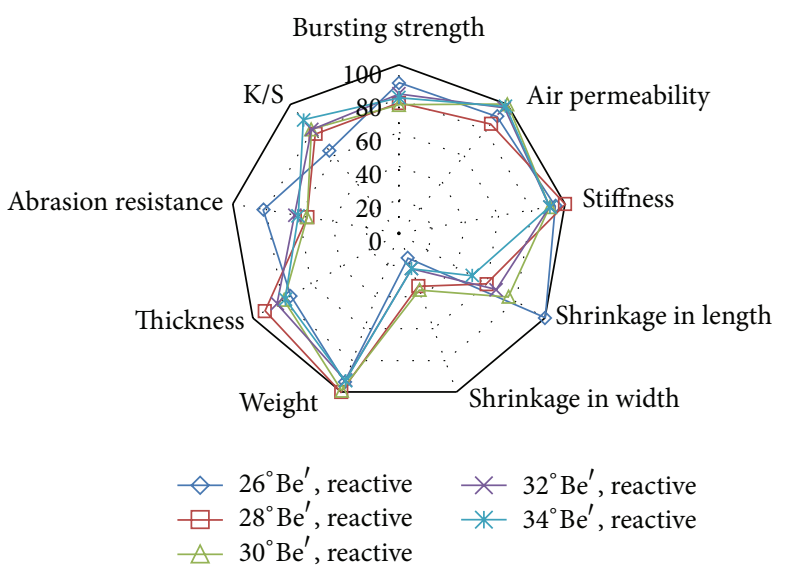

FIgURE 18: Overall evaluation of fabric properties at reactive dyeing.

TABLE 5: Total area of overall fabric properties.

\begin{tabular}{lccccc}
\hline \multirow{2}{*}{ Types of dyeing } & \multicolumn{5}{c}{$\mathrm{NaOH}\left(\mathrm{Be}^{\prime}\right)$} \\
& 26 & 28 & 30 & 32 & 34 \\
\hline Vat dye & $55 \%$ & $56 \%$ & $67 \%$ & $77 \%$ & $68 \%$ \\
Reactive dye & $59 \%$ & $56 \%$ & $58 \%$ & $57 \%$ & $54 \%$ \\
\hline
\end{tabular}

This means that the null hypothesis was not obtained as the yarns properties are not necessarily equal to the properties of fabrics produced from them.

It was noticed that the vat dyeing maintains the physical properties generally more than reactive dyeing.

\section{Conclusion}

(i) Mercerizing process of yarns at different $\mathrm{NaOH}$ concentrations, at $24^{\circ} \mathrm{C}$, followed by bleaching and dyeing with vat and reactive dyeing, has an influence on the final properties of plain jersey fabrics.

(ii) There is an increase of thickness by about $3.4 \%$ to $50 \%$, but mercerized dyed fabrics with vat dyeing are thicker than the reactive ones compared to unmercerized samples. 
(iii) The average increase value of weight is $3.4 \%$ in case of vat dyeing. On the contrary, the average decrease value of weight in case of reactive dyeing is $8.4 \%$ compared to unmercerized samples.

(iv) For the shrinkage in wales direction, the increase in shrinkage for reactive dyeing is less than that for vat dyeing. On the contrary in courses direction, the increase in shrinkage for vat is less than reactive dyeing compared to unmercerized samples.

(v) There is an increase of bursting strength in case of vat dyeing from $0.5 \%$ to $19 \%$ and in case of reactive dyeing from $1.1 \%$ to $18.1 \%$ compared to unmercerized samples.

(vi) Consequently, mercerized plain jersey fabrics dyed with vat dyeing are stiffer than those of the reactive ones.

(vii) There is an increase of the fabric abrasion resistance for vat dyeing from $1.7 \%$ to $62.95 \%$ and for reactive dyeing from $4.8 \%$ to $55.1 \%$ compared to unmercerized samples.

(viii) Mercerized dyed fabrics with vat dyeing have higher air permeability values than reactive dyeing.

(ix) In general, there is an increase of the color properties for both vat dyeing and reactive dyeing compared to unmercerized samples because of the mercerization effect.

(x) From the overall evaluation of physical properties by Performance Diagram, the highest area occurred at $32^{\circ} \mathrm{Be}^{\prime}$ in case of vat dyeing.

(xi) Vat dyeing maintains the physical properties of the fabric generally more than reactive dyeing.

(xii) Analysis of variance showed the properties of yarns and fabrics affected by $\mathrm{NaOH}$ conc. and types of dyeing.

\section{Conflict of Interests}

The authors declare that there is no conflict of interests regarding the publication of this paper.

\section{References}

[1] T. Wakida, M. Lee, S. J. Park, and A. Hayashi, "Hot mercerization of cottons," Fiber, vol. 58, pp. 304-307, 2002.

[2] A. D. Broadbent, Basic Principles of Textile Coloration, Society of Dyers and Colourists, Bradford, UK, 2001.

[3] B. K. Murugesh and M. Selvadass, "Influence of wet processing on properties of single jersey knitted fabrics," International Journal of Fiber and Textile Research, vol. 3, no. 1, pp. 18-30, 2013.

[4] M. Akhbari, A. Zahiri, and S. J. E. Bassam, "Optimization of parameters influencing mercerization using the RSM method in order to increase the tensile strength of mercerized yarn," Fibres \& Textiles in Eastern Europe, vol. 94, no. 5, pp. 30-35, 2012.

[5] N. Samei, S. M. Mortazavi, A. Rashidi, and S. S. Najjar, "Changes in physical properties of hot mercerized ring and open-end spun cotton yarns," Iranian Polymer Journal, vol. 17, no. 12, pp. 937-945, 2008.

[6] R. Gemci, "Examining the effects of mercerization process applied under different conditions to dimensional stability," Scientific Research and Essays, vol. 5, no. 6, pp. 560-571, 2010.

[7] A. R. Moghassem and P. Valipour, "An extensive look in to the effect of mercerization treatment on dimensional properties of cotton plain knitted fabric," Fibers and Polymers, vol. 14, no. 2, pp. 330-337, 2013.
[8] H. Hasani, "Effect of different processing stages on mechanical and surface properties of cotton knitted fabrics," Indian Journal of Fibre and Textile Research, vol. 35, no. 2, pp. 139-144, 2010.

[9] N. Sameii, S. M. Mortazavi, A. S. Rashidi, and S. SheikhzadahNajar, "An investigation on the effect of hot mercerization on cotton fabrics made up of open-end yarns," Journal of Applied Sciences, vol. 8, no. 22, pp. 4204-4209, 2008.

[10] Y. Huh, Y. R. Kim, and W. Oxenham, "Analyzing structural and physical properties of ring, rotor, and friction spun yarns," Textile Research Journal, vol. 72, no. 2, pp. 156-163, 2002.

[11] I. Jordanov, B. Mangovska, and P. F. Tavčer, "Mechanical and structural properties of mercerized cotton yarns, bio-scoured with pectinases," Tekstil, vol. 59, no. 10, pp. 439-446, 2010. 

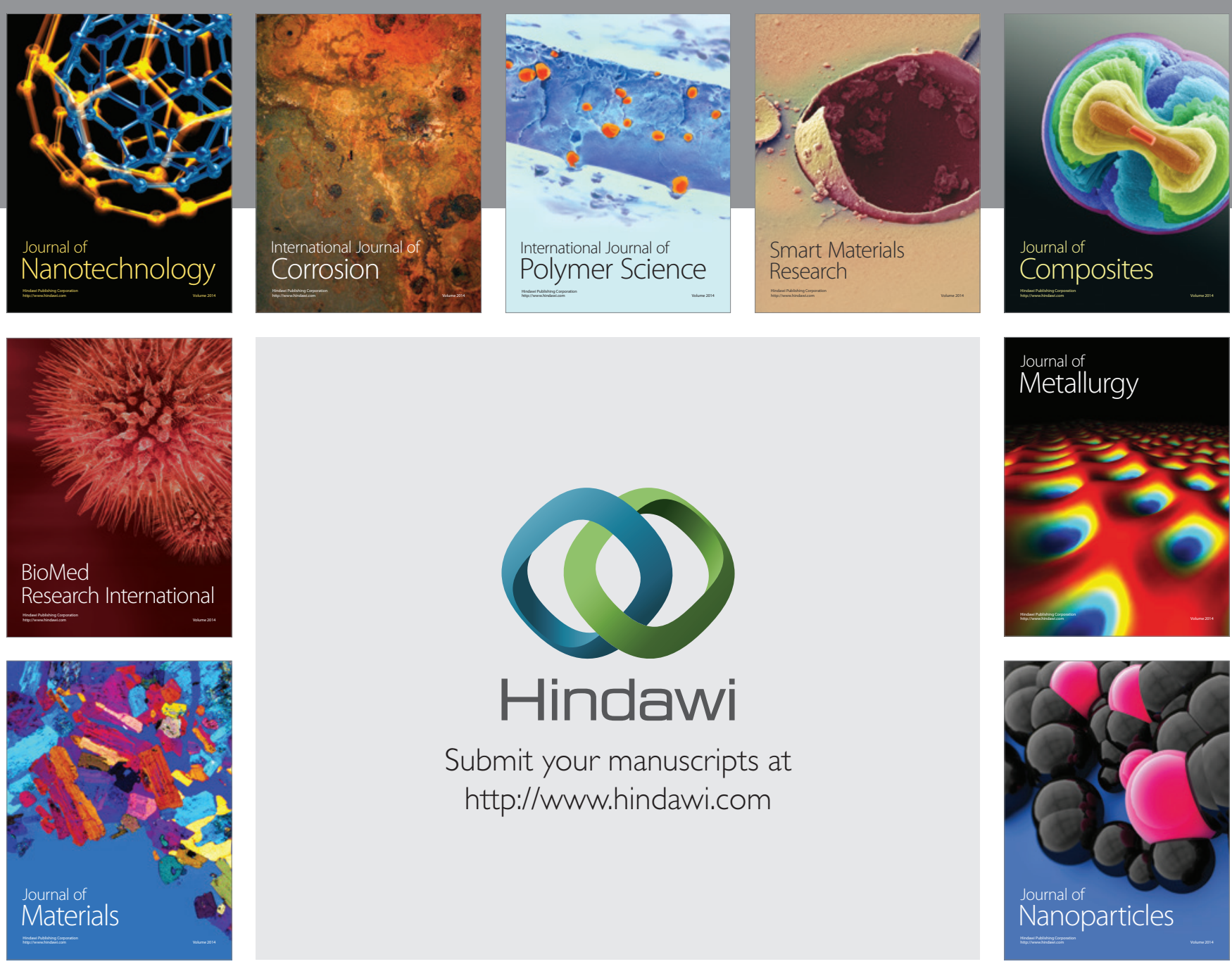

Submit your manuscripts at http://www.hindawi.com
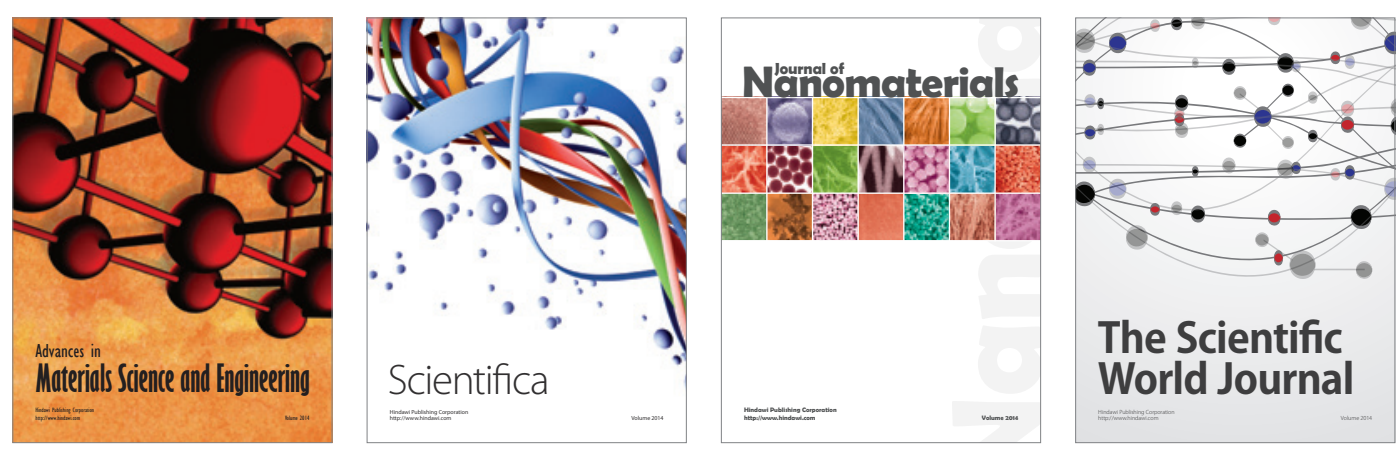

\section{The Scientific World Journal}
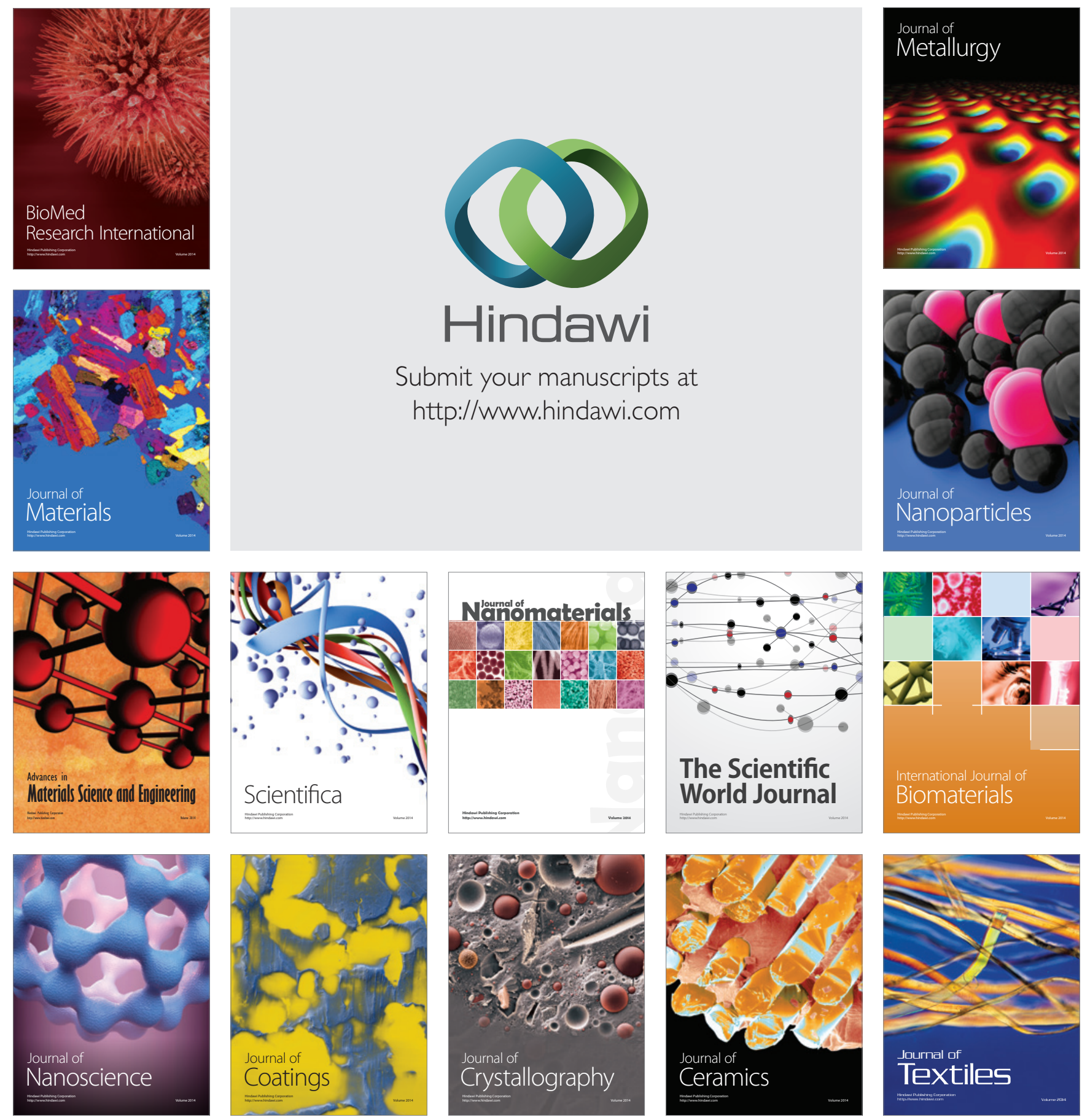